\title{
A DEFINIÇÃO DO ACOMPANHANTE NO PARTO: UMA QUESTÃO IDEOLÓGICA?
}

\author{
SONIA NUSSENZWEIG HOTIMSKY
}

Universidade de São Paulo

AUGUSTA THEREZA DE ALVARENGA

Universidade de São Paulo

\begin{abstract}
Resumo: Discursos médicos, jurídicos e sanitaristas reconhecem a importância que tem a presença do acompanhante no parto. Porém, a definição dessa personagem varia nos diversos discursos em pauta. Descrevemos padróes de acompanhamento na cena do parto em um serviço de saúde 'alternativo' com uma proposta de parto ambulatorial realizado fora do hospital, assistido por obstetrizes, discutindo sua relação com as diferentes formas de sociabilidade, inclusive de relações de gênero, existentes entre as mulheres e os homens de distintas origens sociais que freqüentavam esse serviço. Por fim, discutimos os limites impostos, sobretudo pela legislação estadual de São Paulo e pelo Estatuto da Criança e do Adolescente, ao leque de 'opções' de acompanhante(s) elegidas pelas parturientes e aos membros de suas redes de relações.
\end{abstract}

Palavras-chave: acompanhantes no parto, família, relações de gênero.

Discursos médicos, jurídicos, sanitaristas e acadêmicos reconhecem a importância que tem a presença do acompanhante no parto. ${ }^{1}$ Porém, a definição desse personagem varia nos diversos discursos em pauta. O objetivo deste trabalho é o de confrontar o modo como é definido 'acompanhante' em alguns desses discursos com os padrões de acompanhamento descritos em uma pesquisa acerca de um serviço de saúde 'alternativo' com uma proposta de parto ambulatorial realizado fora do hospital e assistido por obstetrizes.

A Associação Comunitária Monte Azul (ACOMA) é uma instituição antroposófica que, na área de saúde, tem por objetivo prestar assistência aos moradores de duas favelas e do bairro em que se situa na periferia sul do município de São Paulo. Durante os 15 anos em que esteve em funcionamento (1983 a 1998), o serviço de assistência ao parto da ACOMA foi coordenado por Angela Gehrke da Silva, obstetriz formada na Alemanha. Era reconhecido no meio acadêmico, ${ }^{2}$ pela imprensa, por profissionais de saúde, formuladores

\footnotetext{
Copyright $\odot 2002$ by Revista Estudos Feministas

' Este trabalho é elaborado a partir da dissertação de mestrado de Sonia Nussenzweig Hotimsky (HOTIMSKY, 2001). Gostaríamos de agradecer à Maria Luiza Heilborn, à Lia Zanotta Machado, à Claudia Fonseca, à Simone Grilo Diniz, à Maria Luiza Mello de Carvalho, à Maria Lúcia Mott, à Patrícia Logullo e ao Ivan França Junior, cujas reflexões e críticas, em diferentes momentos de elaboração deste trabalho, muito contribuíram para o mesmo.
} 
de políticas públicas e representantes do Ministério de Saúde pela sua qualidade de assistência.

O serviço foi fechado em março de 1998, quando o Conselho Regional de Enfermagem de São Paulo (COREN-SP) notificou Angela Gehrke da Silva e Érika Alfe, outra obstetriz que trabalhou com Angela desde 1996, de que estavam infringindo a lei. ${ }^{3}$ A partir daquele momento não poderiam mais exercer a profissão até regularizar a sua situação, mediante obtenção do diploma de obstetriz ou enfermeira obstétrica no Brasil. Érika deixou de exercer a profissão e Angela fez cursos de adaptação para obter a revalidação de seu diploma de obstetriz na Escola Anna Nery de Enfermagem da Universidade Federal do Rio de Janeiro e pretendia reabrir a Casa de Parto. Entretanto, ao receber a notícia de que a revalidação de seu diploma havia sido aprovada pela Congregação da Escola Anna Nery de Enfermagem, já estava com câncer em estado muito avançado, o qual a levou a falecer em 5 de março de 2000. Embora haja muito interesse, por parte da ACOMA e das mulheres que freqüentavam esse serviço, em abri-lo novamente, a Casa de Parto permanece fechada até hoje.

A descrição e a análise dos padrões de acompanhamento ao parto nesse serviço são baseadas em pesquisa etnográfica, envolvendo observação participante de partos e de consultas de pré-natal assim como entrevistas semi-estruturadas, e em análise de dados quantitativos. Estes últimos são fruto de um levantamento realizado nos Livros de Parto da ACOMA, entre abril de 1985 e março de 1997. Nesse período de 24 meses, 301 'usuárias' e 25 'clientes particulares' foram atendidas no parto pela equipe dirigida por Angela Gehrke da Silva. As denominadas 'usuárias' do serviço eram pessoas das camadas populares urbanas, e as 'clientes particulares' eram pessoas de camadas médias, atendidas no serviço e/ou em domicílio, que compunham a clientela privada das obstetrizes. ${ }^{4}$ Nos registros dos Livros de Parto constam informações sobre a história reprodutiva dessas mulheres, a atual gestação e o trabalho de parto, parto e pós-parto e sobre as pessoas de suas redes de relações que vieram ficar ao seu lado durante esse evento. Os acompanhantes são designados de acordo com a relação que tinham com a parturiente.

Nas últimas consultas do pré-natal, oferecia-se a possibilidade de acompanhamento às mulheres, sugerindo-se, inclusive, que convidassem os companheiros/maridos, quando estes haviam sido mencionados nas consultas, para participarem do nascimento de seus filhos. A presença de acompanhante(s) não era uma exigência do serviço, mas uma livre escolha da mulher, e não havia restrição quanto ao número de pessoas convidadas.

\section{Padrões de acompanhamento}

A grande maioria das mulheres $(82,8 \%$ das 326 atendidas no período de estudo) fez-se acompanhar por uma ou mais pessoas durante o trabalho de parto e/ou parto. A possibilidade de compartilhar essa vivência, e/ou de ter o apoio de uma ou mais pessoas de sua escolha durante esse momento tão significativo em suas vidas, era mencionada

\footnotetext{
2 Ver a respeito Ruth OSAVA, 1997; Regina FIGUEIREDO, 1999; Maria L. RIESCO, 1999; e HOTIMSKY, 2001

${ }^{3}$ Em HOTIMSKY (2001) discutimos brevemente as contingências que levaram ao fechamento desse serviço em 1998. Cabe ressaltar, no entanto, que ao longo dos 15 anos em que esse serviço manteve-se em funcionamento, com o crescente reconhecimento e legitimidade que foi obtendo, não se ignorava o fato que as obstetrizes prestavam assistência sem ter seus diplomas revalidados no Brasil. Aliás, elas haviam empreendido algumas tentativas visando a regularizar sua situação profissional, contando inclusive com o apoio

de usuárias do serviço e profissionais de saúde. Porém todos os esforços tinham sido mal-sucedidos até o momento da intervenção do COREN-SP.

${ }^{4}$ O perfil sócio-epidemiológico dessa clientela encontra-se em HOTIMSKY, 2001.
} 
repetidas vezes nas entrevistas como uma das qualidades do serviço, tanto pelas 'usuárias' como pelas 'clientes particulares', sendo este um dos motivos da sua procura.

A idéia de que a presença de acompanhante(s) no parto seja uma demanda social não apenas entre mulheres de camadas médias, mas também entre mulheres de camadas populares urbanas, é corroborada por resultados de outras pesquisas no Rio de Janeiro ${ }^{5}$ em São Paulo. ${ }^{6}$

Parte significativa dos partos teve acompanhamento por mais de uma pessoa, sendo a média de 1,9 acompanhante por parto. Duas pessoas acompanharam as 'usuárias' em $24,8 \%$ e três ou mais pessoas acompanharam-nas em $25,2 \%$ dos 246 partos acompanhados entre abril de 1991 e março de 1997. Entre as 24 'clientes particulares' acompanhadas atendidas por esse serviço no mesmo período, $25 \%$ foram acompanhadas por duas pessoas e $16,6 \%$ por três ou mais pessoas. No entanto, em nossa pesquisa, o padrão mais freqüente é aquele em que apenas uma pessoa exercia o papel de acompanhante no parto e no nascimento. Esse é o caso de $50 \%$ dos 246 partos acompanhados de 'usuárias' e 58,4\% dos 24 partos de 'clientes particulares' atendidas pelo serviço no período de estudo. A categoria social que mais freqüentemente desempenhava esse papel era o cônjuge, presente em $61,5 \%$ dos partos acompanhados. Seguindo a tendência acima, na maioria das vezes $(55,4 \%$ ou 92 dos 166 partos acompanhados por maridos) em que o cônjuge esteve presente, não era o único acompanhante, havendo, além dele, uma ou mais mulheres. O cônjuge era acompanhante único na cena de parto em apenas $27,4 \%$ ou 74 dos 270 partos acompanhados.

De modo geral, as mulheres que estavam vivenciando a experiência do parto e do nascimento de um/a filho/a pela primeira vez e aquelas com menos filhos é que foram acompanhadas por mais pessoas. Inversamente, entre aquelas com mais filhos, era mais freqüente encontrar mulheres que vinham dar à luz desacompanhadas. Certamente, vários fatores contribuem para essa tendência. Para as mulheres que nunca tiveram filhos, 0 nascimento da primeira criança representa um momento de transição muito importante em suas vidas e talvez, por isso mesmo, desejem compartilhá-lo com seus entes queridos. Como observa Heloisa Paim, ${ }^{7}$ nos grupos populares, a maternidade é vista como condição fundamental da identidade feminina, conferindo status superior às mães em relação às mulheres que não têm filhos. Ao mesmo tempo, o desconhecimento em relação ao funcionamento do próprio corpo e o medo da dor podem ter feito com que as mulheres estudadas sentissem maior necessidade de encorajamento, acolhimento e conforto. As mulheres mais velhas estudadas, por outro lado, que passaram pela experiência de dar à luz pela via vaginal, contam com um saber encorporado ${ }^{8}$ e sentem mais confiança em si e no manejo do próprio corpo, em sua capacidade reprodutiva e de lidar com a dor do parto.

Há que se considerar que, embora minoritária, a parcela de mulheres que vieram desacompanhadas para o parto ou sobre as quais não constam informações sobre a presença de acompanhantes (17,2\%) é digna de atenção. Nem todas as mulheres sem acompanhantes se sentiram desacompanhadas e desamparadas no parto, como sugere o depoimento de Sirlene abaixo, ao comparar o parto e o nascimento hospitalar de seu primeiro filho com os do segundo e do terceiro filhos, nascidos no ambulatório da ACOMA:

\footnotetext{
${ }^{5}$ Rosa DOMINGUES, 2000; Maria Luiza CARVALHO, 2001.

${ }^{\circ}$ OSAVA et al. , 2000

7 PAIM, 1998, p. 35.

${ }^{8}$ Acerca da concepção de saber encorporado, ver Thomas CSORDAS, 1994.
} 
No hospital é diferente, é você e Deus lá largado (...) dona Ângela estava ali me dando um tratamento especial, (...) compartilhando, (...) entendeu? Então, é como eu te falo (...) [ela] sabe conversar com você, porque é difícil, entendeu? (...) a dona Ângela (...) estava ali (...) perguntando o que você estava precisando, quer dizer, era como se uma amiga tivesse ali $(\ldots)$.

Para muitas das mulheres entrevistadas, o acolhimento que receberam das obstetrizes foi diferente daquele recebido em hospitais. Sirlene, aliás, assemelha a atenção da obstetriz Angela àquela que seria prestada por uma amiga, categoria social que aparece com maior freqüência entre as acompanhantes de sexo feminino $(41,2 \%)$.

Parte das mulheres, provavelmente, veio sozinha por não ter alguém com quem quisesse ou pudesse compartilhar essa experiência, mas é possível, também, que uma parcela delas tenha optado por vir sozinha. Isto é, para algumas mulheres, o desejo de preservar a privacidade significava dar à luz apenas na presença da profissional responsável pela assistência. $O$ fato de o parto desacompanhado ser mais freqüente entre mulheres mais velhas, e com três ou mais filhos, talvez sustente essa hipótese, já que um maior recato e modéstia em relação à sexualidade e à reprodução parecem estar mais próximos de padrões 'tradicionais' de gerações anteriores.

Há diferenças marcantes na distribuição de acompanhantes segundo sexo e camada social. Há uma proporção bem maior de acompanhantes de sexo feminino $(64,0 \%)$ do que do masculino (36,0\%) no total de 525 acompanhantes. A proporção de partos acompanhados por mulheres é significativa tanto entre as 'clientes particulares' $(50 \%$ dos 24 partos acompanhados) como entre as 'usuárias' (72,8\% dos 246 partos acompanhados). Ressalta-se que aqueles acompanhados exclusivamente por mulheres, os quais representam $33,3 \%$ do total de partos acompanhados, ocorrem majoritariamente ( $97,8 \%$ dos 90 casos) entre mulheres de camadas populares. A proporção de mulheres sem cônjuges era maior nessa população, em que também era mais comum os homens não poderem se ausentar de seus trabalhos para assistir ao parto e ao nascimento de seus filhos. Porém, noções de pudor feminino também contribuíram para manter os homens afastados da cena do parto entre a clientela de camadas populares. Associado ao pudor, em alguns casos, nota-se que a percepção da vagina como uma parte feia do corpo feminino e/ou a referência específica à posição de parir, assim como a visualização da criança saindo da vagina como algo feio, assustador ou nojento, foi explicitado por algumas mulheres das camadas populares por nós entrevistadas. ${ }^{10} \mathrm{~A}$ inibição frente ao parceiro sexual, qualquer que seja sua motivação, leva algumas mulheres a preferir a companhia de mulheres, enquanto outras buscam negociar com seus cônjuges a posição em que estes permanecem na cena do parto, procurando se preservar do seu olhar ou garantir um certo controle sobre seu campo de visão durante esse evento.

Quanto às categorias sociais de acompanhantes considerados apropriados, há novamente uma nítida distinção entre os sexos, o que desvela a presença de concepções de sexualidade e gênero que norteiam as escolhas possíveis. Entre os acompanhantes homens, há preferência por parentes, os quais representam $98,9 \%$ destes. Destaca-se entre estes a categoria social de cônjuge, que representa $87,4 \%$ dos acompanhantes de sexo masculino (Tabela 1). Aspectos do parto e do nascimento percebidos como relacionados à modéstia e ao recato fariam com que a presença de outros homens fosse vista como

\footnotetext{
${ }^{9}$ Os nomes das entrevistadas são fictícios.

${ }^{10}$ A esse respeito ver HOTIMSKY, 2001, e também CARVALHO, 2001.
} 
uma invasão da intimidade e privacidade da mulher. Nota-se que, nesse sentido, não há diferenças significativas entre as clientelas de camadas populares e médias.

\section{Tabela 1 - Distribuição dos 190 acompanhantes de sexo} masculino segundo as categorias sociais de acompanhantes nos 270 partos acompanhados atendidos pelo serviço de atenção ao parto da ACOMA entre abril de 1995 e março de 1997

\begin{tabular}{|c|c|c|c|c|c|c|}
\hline \multirow[t]{2}{*}{$\begin{array}{l}\text { CATEGORIAS } \\
\text { SOCIAIS }\end{array}$} & \multicolumn{2}{|c|}{ USUÁRIAS' } & \multicolumn{2}{|c|}{$\begin{array}{c}\text { 'CLIENTES } \\
\text { PARTICULARES' }\end{array}$} & \multicolumn{2}{|c|}{ TOTAL } \\
\hline & N. ${ }^{\circ}$ & $\%$ & $\mathrm{~N} .{ }^{\circ}$ & $\%$ & N. ${ }^{\circ}$ & $\%$ \\
\hline \multicolumn{7}{|l|}{ PARENTES } \\
\hline Marido & 145 & 87,4 & 21 & 87,5 & 166 & 87,4 \\
\hline Irmão(s) & 7 & 4,2 & 1 & 4,2 & 8 & 4,2 \\
\hline Pai & 7 & 4,2 & 2 & 8,3 & 9 & 4,7 \\
\hline Outro(s) & 5 & 3,0 & - & - & 5 & 2,6 \\
\hline SUBTOTAL PARENTES & 164 & 98,8 & 24 & 100,0 & 188 & 98,9 \\
\hline \multicolumn{7}{|l|}{ SEM PARENTESCO } \\
\hline $\begin{array}{l}\text { Filhos de Amigas } \\
\text { Outro(s) }\end{array}$ & 2 & 1,2 & - & - & 2 & 1,1 \\
\hline $\begin{array}{l}\text { SUBTOTAL SEM } \\
\text { PARENTESCO }\end{array}$ & 2 & 1,2 & - & - & 2 & 1,1 \\
\hline TOTAL & 166 & 100,0 & 24 & 100,0 & 190 & 100,0 \\
\hline
\end{tabular}

Fonte: Livro de Partos da ACOMA

Por outro lado, entre as acompanhantes de sexo feminino, tanto parentes $(54,6 \%)$ como não-parentes $(45,4 \%)$ podiam ser consideradas pessoas 'apropriadas' para desempenhar esse papel, o qual era realizado por diversas categorias sociais. Isoladamente, a categoria social de acompanhante feminina mais freqüente, tanto entre as 'usuárias' $(41,2 \%)$ como entre as 'clientes particulares' (41,2\%), foi a 'amiga' (Tabela 2). O fato de a 'amiga' ser recrutada com tanta freqüência para desempenhar esse papel nos dois grupos estudados nos leva a rechaçar a idéia de que o parto e o nascimento seja um fenômeno social referente única e exclusivamente à família. À medida que outros membros da rede de relações sociais da mulher são convidados 
a participar do evento e a lhe prestar seu apoio emocional, percebe-se que outras formas de reciprocidade e solidariedade, além daquelas referentes ao parentesco, se explicitam e podem até se fortalecer por intermédio do parto.

A inserção da amiga na cena de parto também parece explicitar, nesse evento, uma das mudanças nos padrões de sociabilidade, mais geral, que caracteriza a migração do meio rural para o meio urbano-industrial. No meio urbano, como se sabe, as redes de relações sociais vão se diversificando e novas formas de sociabilidade, que não aquelas associadas às relações de parentesco, vizinhança e compadrio, vão ganhando importância. A opção por buscar o suporte emocional da amiga, particularmente para mulheres de camadas populares - entre as quais o primeiro parto pode representar uma mudança de status importante no curso vital ${ }^{11}$-, é, nesse sentido, uma demonstração da importância que essa categoria social vem adquirindo junto a mulheres dessa origem social.

Ao voltar nossa atenção para as parentes de sexo feminino presentes nesse evento, nota-se que há um número bem menor destas entre as 'clientes particulares' (Tabela 2).

\section{Tabela 2 - Distribuição das 335 acompanhantes de sexo feminino segundo as categorias sociais de acompanhantes nos 270 partos acompanhados atendidos pelo serviço de atenção ao parto da ACOMA entre abril de 1995 e março de 1997}

\begin{tabular}{|c|c|c|c|c|c|c|}
\hline \multirow[t]{2}{*}{$\begin{array}{l}\text { CATEGORIAS } \\
\text { SOCIAIS }\end{array}$} & \multicolumn{2}{|c|}{ 'USUÁRIAS' } & \multicolumn{2}{|c|}{$\begin{array}{c}\text { 'CLIENTES } \\
\text { PARTICULARES' }\end{array}$} & \multicolumn{2}{|c|}{ TOTAL } \\
\hline & N. ${ }^{\circ}$ & $\%$ & N. ${ }^{\circ}$ & $\%$ & N. ${ }^{\circ}$ & $\%$ \\
\hline \multicolumn{7}{|l|}{ PARENTES } \\
\hline Mãe & 57 & 17,9 & & 23,5 & 61 & 18,2 \\
\hline Sogra & 19 & 2,8 & 1 & 5,9 & 10 & 3,0 \\
\hline Tia(s) & 16 & 5,0 & & & 16 & 4,8 \\
\hline Irmãa(s) & 39 & 12,3 & $\overline{5}$ & $2 \overline{9}, 4$ & 44 & 13,1 \\
\hline Cunhada(s) & 22 & 6,9 & _ & - & 22 & 6,6 \\
\hline Prima(s) & 13 & 4,1 & - & - & 13 & 3,9 \\
\hline Filha(s) & 5 & 1,6 & - & - & 5 & 1,5 \\
\hline Outra(s) & 12 & 3,8 & - & - & 12 & 3,6 \\
\hline \multicolumn{7}{|l|}{ SUBTOTAL } \\
\hline PARENTES SEM PARENTESCO & 173 & 54,4 & 10 & 58,8 & 83 & 54,6 \\
\hline Amigas & 131 & 41,2 & 7 & 41,2 & 138 & 41,2 \\
\hline Vizinhas & 12 & 3,8 & & . & 12 & 3,6 \\
\hline Outra(s) & 2 & 0,6 & & & 2 & 0,6 \\
\hline SUBTOTAL SEM PARENTESCO & 145 & 45,6 & $\overline{7}$ & $4 \overline{1}, 2$ & 152 & 45,4 \\
\hline TOTAL & 318 & 100,0 & 17 & 100,0 & 335 & 100,0 \\
\hline
\end{tabular}

Fonte: Livros de Partos da ACOMA

\footnotetext{
1 Acerca da mudança de status associada ao primeiro parto entre mulheres das camadas populares, ver PAIM, 1998; e Rosely COSTA, 1995.
} 
Pudemos identificar apenas três categorias de parentes entre as acompanhantes das 'clientes particulares' - a mãe, a irmã e a sogra. Entre as 'usuárias', encontramos essas três e mais quatro categorias: cunhada, tia, prima e filha. Evidentemente, a quantidade de partos registrados em cada caso não é comparável e pode ter influenciado os resultados. Por outro lado, esses dados não deixam de ser sugestivos, porque parecem refletir a tendência existente entre as camadas médias, a 'nuclearização' da família, enquanto que, entre as camadas populares, é freqüente encontrarmos formas de organização familiar mais extensas ou ampliadas, o que talvez nos ajudasse a entender a presença de tias e primas, consangüíneas mais distantes, entre as acompanhantes. As consangüíneas da parturiente prevalecem entre as parentes, o que talvez seja indicativo do papel mais ativo que ela desempenha no recrutamento de acompanhantes no parto, mesmo quando seu marido está presente. Afinal, entre as camadas populares brasileiras, e mesmo entre alguns setores das camadas médias, os laços de consangüinidade tendem a ser mais fortes do que os laços de afinidade. ${ }^{12}$ Ao mesmo tempo, não podemos perder de vista que se trata de um evento que envolve a sexualidade e implica exposição corporal da mulher dando à luz, o que pode acarretar sentimentos de inibição mesmo em relação a mulheres com as quais tem menor intimidade. Em todo caso, fica claro que noções de 'apoio emocional', 'intimidade', 'privacidade' e 'inibição' são construções culturais e, por isso mesmo, apresentam diversas definições e interpretações.

Nem sempre as acompanhantes eram mães. Esse fato aparentemente diferencia os padrões observados neste estudo daqueles que caracterizam o parto com parteiras no meio rural e parece explicitar uma mudança significativa em relação às concepções de sexualidade e reprodução. As mulheres de camadas populares deste estudo que foram acompanhadas por outras pessoas em partos anteriores, realizados por parteiras tradicionais, o foram por mulheres sabidamente 'experientes' sexual e reprodutivamente, enquanto, segundo nos informaram, esse evento era interditado para as acompanhantes mais jovens e sem filhos, que se pressupunham 'inexperientes'. Aparentemente, esse tipo de diferenciação não faz sentido no contexto desse serviço. É possível, inclusive, que um dos motivos pelos quais mulheres da mesma geração acompanhavam os partos de suas amigas, vizinhas e parentes seja que, além de querer compartilhar a emoção desse evento, algumas delas tenham desejado a oportunidade de presenciar a 'novidade' desse modelo de atenção, considerando a possibilidade de virem a ter seus bebês fora do hospital. Além disso, por ser uma proposta diferente, talvez tenha contado menos com a aprovação das mães e sogras, presentes em alguns partos, mas com menos freqüência que as amigas. Em todo caso, fazer o parto no ambulatório do ACOMA representava, para a grande maioria das mulheres, tanto de camadas populares como de camadas médias, um marco de diferenciação em relação às suas mães e às gerações anteriores.

A presença marcante do acompanhante do sexo masculino na cena do parto e, em particular, do cônjuge constitui um indício das transformações em curso nas construções de gênero e de família. Esse fato sinaliza uma mudança nos valores em relação a esse evento, o qual não é mais percebido pela maioria das pessoas atendidas por esse serviço, tanto 'usuárias' quanto 'clientes particulares', como 'coisa de mulher'. Cabe, porém, observar que, comparando-se 'usuárias' (64,2\% das 246 eram acompanhadas por homens) com 'clientes particulares' ( $91,7 \%$ das 24 eram acompanhadas por homens), a maior proporção de partos não acompanhados por homens ocorre entre as primeiras. Isso, entre outros

\footnotetext{
${ }^{12}$ Claudia FONSECA, 2000.
} 
motivos, por não terem cônjuges ou por estes não considerarem apropriada sua presença nesse evento ou não terem disponibilidade para tal.

Os dados deste estudo indicam que há diversas formas de inserção desse novo personagem no parto, e diversos sentidos que sua presença pode adquirir para ele, para a parturiente e para as demais pessoas presentes, como também observa Carvalho em seu estudo sobre a participação do pai no nascimento da criança em um ambiente hospitalar. ${ }^{13}$ Para algumas mulheres e seus cônjuges, a participação destes últimos nesse evento representou uma oportunidade de acompanhar mais de perto e de forma mais ativa o nascimento de seus filhos/as. Observamos que, na cena do parto, a maior adesão do cônjuge ao ritual proposto pelo serviço - o acompanhante era convidado a cortar 0 cordão umbilical e a dar o primeiro banho - ocorreu entre as camadas médias. Estas são o referente sociológico do ideário de 'família moderna'14 e do 'casal grávido'15 responsável pela construção social desse rito. Esse ideário teria por bases três princípios estruturantes, os quais, por sua vez, seriam elementos constitutivos da ordem social e ideologia individualista que caracterizaria a moderna sociedade ocidental. Para Salém, os três princípios estruturantes do 'casal grávido' são: 1) o da psicologicidade, que se refere a uma tendência à individualização, interiorização e privatização de cada um dos cônjuges e do casal vis-a-vis as suas respectivas famílias de origem e a sociedade como um todo; 2) o da igualdade, que se refere a uma oposição a englobamentos e a ordenamentos hierárquicos e uma valorização da indiferenciação em relação aos papéis conjugais e do estabelecimento de relações de reciprocidade igualitárias, isto é, pautadas por uma complementaridade simétrica; (3) o da mudança, que se refere a um movimento de autoaperfeiçoamento e de libertação.

Por outro lado, entre as 'usuárias' e seus cônjuges, havia aqueles que valorizavam a participação destes no evento porque 'ver o sofrimento' de suas mulheres os levava a thes 'dar mais valor'. Nesse discurso, a dor do parto é 'naturalizada' como sofrimento inerente à maternidade e marco de transição para a obtenção do status de mulher adulta. ${ }^{16} \mathrm{O}$ 'sofrimento' no parto é uma fonte tradicional de prestígio e auto-estima entre mulheres em contextos em que predomina uma nítida segregação dos papeis sexuais, sendo parte constitutiva da construção social de gênero prevalecente entre as camadas populares brasileiras, ${ }^{17}$ como em vários outros contextos culturais. ${ }^{18}$ Percebe-se, portanto, que a presença do marido no parto nem sempre implica uma aproximação com o ideário do 'casal grávido' e da 'família moderna' no sentido da valorização da indiferenciação em relação aos papéis conjugais. Ao contrário, a presença dos maridos no parto pode vir a reforçar, em um novo contexto, valores 'tradicionais' existentes.

Ademais, a entrada em cena desse novo ator não substitui, em muitos casos, a presença feminina. Nesse sentido, é interessante notar que, entre os partos com mais de um acompanhante, o padrão mais freqüente envolve conjuntos de pessoas de ambos os sexos. Em apenas um caso havia dois homens como acompanhantes. Ao todo, 29,3\% dos

\footnotetext{
${ }^{13}$ CARVALHO, 2001.

${ }^{14}$ Ver FONSECA, 1997.

${ }^{15}$ Ver Tânia SALÉM, 1989.

16 FIGUEIREDO (1999), por outro lado, sugere que as mulheres queriam que seus maridos estivessem presentes na cena de parto para que pudessem expressar sua insatisfação frente às desigualdades vivenciadas nas relações de gênero e explicitar seu desejo por mudanças. É assim como essa autora interpreta o desejo explicitado por algumas mulheres de que seus maridos pudessem ver seu sofrimento como forma de lhes dar valor.

17 Ver PAIM, 1998; e COSTA, 1995.

18 Ver a respeito Margaret MEAD e Newton NILES, 1967; e Carole BROWNER e Carolyn SARGENT, 1996.
} 
270 partos acompanhados o eram exclusivamente por homens, 33,3\% eram acompanhados exclusivamente por mulheres e $37,4 \%$ eram acompanhados por conjuntos de homens e mulheres.

Talvez isso seja mais um indício de como as concepções de gênero orientam as 'opções' em relação ao acompanhamento. Sugerimos que, para muitos dos sujeitos dessa pesquisa, a presença de seus companheiros nesse evento, embora muito valorizada, não significa que eles tenham desempenhado determinados papéis de apoio, considerados de âmbito feminino. Isto é, a permanência da acompanhante feminina por vezes implicava uma diferenciação de papéis dos acompanhantes, segundo noções de gênero. É o que sugerem alguns depoimentos prestados e as observações de alguns partos durante a pesquisa de campo. Pudemos notar que, por vezes, homens e mulheres prestam apoio de formas diferenciadas na cena de parto. É mais comum, por exemplo, as acompanhantes terem mais contato corporal com as mulheres durante o parto, enquanto que os homens, por vezes, ficam mais retraídos e afastados do contato físico com suas mulheres. ${ }^{19}$ Algumas 'usuárias', por exemplo, referiam que suas acompanhantes Ihes "alisaram" e "acarinharam" e algumas 'clientes particulares' solicitaram, preferencialmente, de suas acompanhantes que Ihes fizessem "massagens".

Ao mesmo tempo, algumas mulheres entrevistadas também manifestaram a opinião de que suas acompanhantes podiam desempenhar um papel diferente dos homens. Diz Vera, uma das 'clientes particulares':

Quando eu chamo a Nara, eu sei que eu posso confiar na Nara (...) é uma mistura de confiança com sensibilidade, eu sei que eu posso puxar uma sensibilidade quando eu estou com uma amiga que é diferente da sensibilidade que eu tenho com meu marido, que é diferente da sensibilidade que eu tenho com a Ângela, certo? A Ângela está lá na coisa profissional, o André ia estar lá numa tensão assim de marido, e se eu precisasse de alguma coisa assim mais emocional (...) acho que eu ia recorrer à amiga, sabe?

\section{O acompanhante no parto segundo discursos médicos, jurídicos, sanitaristas e acadêmicos}

Nos últimos anos, diversos atores sociais têm se empenhado na criação, promoção e implementação de novos direitos reprodutivos. Entre esses figuram o direito da mulher à assistência apropriada em relação à gravidez, ao parto e ao período posterior ao parto. Esse direito é explicitado na Convenção sobre a Eliminação de Todas as Formas de Discriminação contra a Mulher de 1979, em que se afirma que a mulher tem direito a "assistência apropriada no pré-parto, parto e puerpério", ${ }^{20}$ e reiterado na Conferência Mundial de Direitos Humanos, em que se

(...) reafirma, com base no princípio de igualdade entre mulheres e homens, o direito da mulher a uma assistência de saúde acessível e adequada e ao leque mais amplo possível de serviços de planejamento familiar (...). ${ }^{21}$

\footnotetext{
${ }^{19}$ A respeito dessa tendência de retraimento dos homens ver também Lucineide BESSA e Sílvia FERREIRA, 1999; e CARVALHO, 2001.

${ }^{20}$ Convenção..., artigo 12, inciso 2 (NAÇÕES UNIDAS, 1979, p. 6).

${ }^{21}$ Vienna Declaration and Programme of Action, 1993, part II B, section 3, article 41 (UNITED NATIONS, 1993, p. 17).
} 
Essa categoria de direitos foi recentemente denominada de direitos relativos ao parto e ao nascimento, ${ }^{22}$ e a definição do que seja "assistência apropriada" à saúde da mulher e do bebê vem sendo objeto de embates e de negociações envolvendo diversos atores sociais, profissionais engajados nas áreas da saúde e dos direitos humanos, e tem resultado na produção de múltiplos discursos. ${ }^{23}$

Recomendações e leis de âmbitos nacional e internacional, assim como os discursos de formuladores de políticas públicas, sanitaristas e médicos, reconhecem a importância que tem a presença do acompanhante no parto. Porém, a definição desse personagem varia nos diversos discursos em pauta. Pretendemos discutir até que ponto os discursos em pauta promovem e protegem o direito humano à assistência apropriada no parto e no nascimento.

Existem indícios de que haja uma associação consistente e significativa entre dimensões do suporte social - isto é, a percepção subjetiva que se tem do apoio emocional e social daqueles que nos cercam - e a saúde. Para diversos pesquisadores, o suporte social é uma das dimensões subjetivas que devem ser incluídas em pesquisas sobre qualidade de vida, ${ }^{24}$ saúde mental, estresse, pressão alta, diabete ${ }^{25}$ e sobre o nascimento e parto.

Particularmente em relação ao nascimento e parto, as evidências científicas apontam para $o$ fato de que a presença de acompanhante contribui para o seguro transcorrer do trabalho de parto, parto e pós-parto, facilitando esse processo, com conseqüente melhoria dos indicadores de saúde da mulher e do recém-nascido e do bem-estar de ambos. ${ }^{26}$ Cabe ressaltar que os trabalhos inclusos na revisão sistemática, empreendida para a Biblioteca Cochrane, ${ }^{27}$ mostram que a presença de acompanhante que garanta apoio contínuo, ao longo do trabalho de parto e pós-parto, reduz significativamente o percentual de partos cesáreos, a duração do trabalho de parto, a utilização de analgesia/anestesia e de ocitocina, e a hospitalização prolongada dos recémnascidos. ${ }^{28}$ Foram essas evidências que levaram a Organização Mundial de Saúde (OMS) a recomendar, na Conferência sobre Tecnologias Apropriadas para o Nascimento e Parto, em 1985, a presença do acompanhante durante o parto e o nascimento:

O bem-estar da nova mãe deve ser assegurado através do livre acesso, de um membro da família, de sua escolha, ao parto, nascimento e durante o período puerperal. Além disso, a equipe de saúde deve proporcionar-Ihe apoio emocional. ${ }^{29}$

\footnotetext{
${ }^{22} \mathrm{Em} 2001$, a Panos, uma instituição sem fins lucrativos que fornece informações sobre questões globais a partir de uma perspectiva que afirma ser de "países em desenvolvimento", lançou um documento, intitulado Birth Rights. New Approaches to Safe Motherhood, em que constrói e defende essa nova categoria de direitos - os direitos relativos ao parto e ao nascimento.

${ }^{23}$ Ver, a respeito das múltiplas definições de 'humanização do parto e nascimento', Carmen DINIZ, 2001; e Carmen TORNQUIST, 2001.

${ }^{24}$ Eduardo FAERSTEIN, 2000.

${ }^{25}$ William Dressler, mauro Balieiro e Jose Santos, 1997; e Mariana

Ferreira, 1996.

${ }^{26}$ Ellen HODNETT, 2000; DOMINGUES, 2000; Jo CZANOCKA e Pauline SLADE, 2000; B. C. MADI et al., 1999; Murray ENKIN et al., 1995; Wendy-Lynne WOLMAN et al., 1993; John KENNELL et al., 1991; G. Justus HOFMEYR et al., 1991; lain CHALMERS et al., 1989; e Marshall KLAUS et al., 1986.

${ }^{27}$ HODNETT, 2000.

${ }^{28}$ Para outras informações ver as publicações acima citadas.

${ }^{29}$ World Health Organization, 1985, p. 437.
} 
Essa recomendação da OMS abre um leque de opções à mulher, pois reconhece que cabe a ela escolher o acompanhante. Entendemos que há, nessa recomendação, um reconhecimento implícito de que as formas de apoio à mulher e ao bebê nesse evento são social e culturalmente construídas. Por isso mesmo, elas variam, segundo o contexto social, sendo moduladas a partir de diferentes valores culturais, e a mulher sofre constrangimentos de diversas ordens. Efetivamente, como mostram Mead e Newton, ${ }^{30}$ na maioria das sociedades e culturas humanas as mulheres são acompanhadas durante $\circ$ parto e o nascimento. Na década de 1960, quando da realização daquele levantamento, a demanda por acompanhamento em partos hospitalares apenas se iniciava. Entre os acompanhantes existentes nos diversos contextos socioculturais onde sua presença era permitida, predominavam as mulheres mais velhas. Essas últimas não eram necessariamente parentes da mulher dando à luz, o que revela, por outro lado, o caráter restritivo da recomendação da OMS de 1985, que limita o conjunto de opções de acompanhantes disponíveis à mulher aos membros de sua família.

Além disso, há implícita, na recomendação da OMS acima citada, uma naturalização da maternidade. É o bem-estar da 'nova mãe' que se pretende assegurar por intermédio dessa medida de suporte social. Pressupõe-se que, no transcorrer desse evento, a mulher que está dando à luz, e somente ela, vai se transformar necessariamente em mãe do bebê que está nascendo. Porém, nem todas as mulheres que dão à luz tornam-se mães. Algumas exercem o direito reprodutivo de dar o bebê para adoção. Fatores relacionados à qualidade e oferta de opções de planejamento familiar e ao âmbito bastante circunscrito em que se oferece a oportunidade de se realizar o aborto legalmente no Brasil certamente criam constrangimentos ao exercício de escolhas reprodutivas e contribuem para o aumento de casos de adoção no País. Este fato é relevante, considerando-se sua elevada prevalência no Brasil. ${ }^{31}$

Algumas famílias pobres dão seus bebês para 'adoção plena'. Ao seguir os trâmites estabelecidos pela legislação, a qual envolve a idéia de filiação substitutiva, terão de abrir mão da maternidade, da paternidade e de outros laços de consangüinidade. Outras famílias não irão abrir mão das relações de parentesco com o recém-nascido, pois vão compartilhar a maternidade e/ou outras relações de parentesco com uma ou mais mulher(es) e seus familiares, membro(s) da rede de relações sociais de um ou ambos os genitores, conforme a tradição muito presente desde o período colonial, e atualmente em vigor entre as camadas populares, de 'circulação de crianças'. ${ }^{22}$ Nesse caso, mais de uma mãe e/ou pai e/ou parente podem emergir da cena do parto. É o que ocorreu em um caso de adoção registrado nos Livros de Partos da Associação Comunitária Monte Azul entre abril de 1995 e março de 1997.

Consta nos registros do parto de Inês, de 25 anos, mãe de uma menina de dois anos, que ela estava dando seu segundo filho para uma irmã adotar. Cabe ressaltar que essa irmã viera acompanhar o parto de Inês. Chama a atenção o vínculo estabelecido com a obstetriz, Angela Gehrke da Silva. O fato de partilhar com a profissional a intenção de dar seu filho para adoção indica que, pelo menos em alguns casos, as mulheres não temiam a reprovação moral dela, que soube dar suporte à parturiente em relação ao exercício de um direito reprodutivo - o direito de dar seu filho para adoção.

A presença da irmã da genitora, registrada no Livro de Parto como "irmã que adota", na cena de parto é, ademais, uma manifestação do suporte dado às formas de organização

\footnotetext{
30 MEAD E NEWTON, 1967.

${ }^{31}$ A esse respeito ver FONSECA, 1998.

32 FONSECA, 1995.
} 
familiar alternativas que puderam se explicitar por intermédio desse evento. Vale destacar que Inês não está, necessariamente, abrindo mão da maternidade, mas, conforme a tradição de circulação de crianças, pode estar partilhando a maternidade com sua irmã desde a cena do parto e do nascimento de seu filho. Nesse caso, o evento pode estar representando um momento dentro de um processo de construção da pluriparentalidade, tal como freqüentemente ocorre entre as camadas populares.

Atualmente, com a implementação das modernas tecnologias reprodutivas, emergem novas restrições em relação ao uso de uma concepção naturalizada da maternidade, da paternidade e/ou da família ${ }^{33}$ para compreender 0 que se passa na cena do parto.

A concepção de que o acompanhante deve ser de escolha da mulher que está parindo, sem restrições quanto à sua relação com ela ou ao sexo do acompanhante, mas ainda mantendo uma restrição quanto ao número de acompanhantes, transparece em um documento do Instituto Panos. Os autores desse documento defendem uma concepção de assistência ao parto e ao nascimento "centrada na mulher" e afirmam que, nesse evento, "suporte social significa prestar atenção aos desejos da mulher, seu sentimento de bem-estar, suas demandas por informações e suas escolhas". ${ }^{34}$

Além de argumentar que deixar de atender às necessidades de gestantes e parturientes é uma injustiça social de grandes proporções, os autores desse documento propõem que a Iniciativa Maternidade Segura amplie seu âmbito de atuação, incorporando a promoção e proteção da assistência apropriada à gravidez, ao parto e ao pós-parto de maneira global, tal como explicitado no artigo 12 da Convenção sobre a Eliminação de Todas as Formas de Discriminação contra a Mulher e reiterado na Declaração de Viena.

Não obstante tais recomendações, políticas ainda mais restritivas com relação à presença de acompanhantes nos partos e nos nascimentos são implementadas em hospitais situados em diversos países..$^{35}$ No Brasil, o Ministério de Saúde recentemente reconheceu o direito da gestante ao acompanhamento por pessoa de sua escolha durante o trabalho de parto. Nota-se que, se a escolha de acompanhante é livre, ainda se restringe a um acompanhante, e seu acesso à mulher dando à luz se limita ao período em que esta se encontra em trabalho de parto. ${ }^{36}$

Cabe salientar que se trata de uma recomendação e não de uma medida legal, e seu impacto é ainda tênue. Assim, no Brasil, a grande maioria das maternidades públicas ou conveniadas ao Sistema Único de Saúde (SUS) ainda não permite a presença de acompanhante durante o parto e o nascimento. Conseqüentemente, as mulheres brasileiras, na sua maioria, dão à luz desacompanhadas. Aliás, uma das queixas freqüentes de mulheres

\footnotetext{
33 FONSECA, 1998.

${ }^{34}$ PANOS INSTITUTE, 2001, p. 35.

${ }^{35}$ Ver, a esse respeito, a revisão sistemática da Cochrane Library, HODNETT, 2000, p. 18-22, e PANOS INSTITUTE, 2001 p. 33 e 35. Nesses trabalhos pode-se observar que em muitos países não é permitido o acompanhante no parto e, quando o é, se restringe a apenas uma pessoa, sendo essa freqüentemente preestabelecida pela instituição como o pai e/ou familiar.

${ }^{36}$ BRASIL, 2001, p. 64. Segundo o mesmo documento, observa-se que "O direito ao acompanhamento da gestante é já reconhecido em diversas instâncias, incluindo o Ministério da Saúde, entretanto não é praticado de forma regular e sistemática em todo o país. Ao contrário, de maneira geral, apenas as mulheres mais favorecidas economicamente, que têm seus partos através de seguros em hospitais privados, é que utilizam deste direito" (BRASIL, 2001, p. 64). Nessas circunstâncias há de se perguntar se é um direito ou um privilégio. A publicação e distribuição deste manual podem ser interpretados como uma medida de promoção, porém não se trata de uma medida de proteção deste direito ou de garantia de sua implementação como caberia aos Estados-Nações signatários da Convenção sobre a Eliminação de Todas as Formas de Discriminação Contra a Mulher e da Declaração de Viena.
} 
de camadas populares e médias acerca de suas experiências de parto é o isolamento em relação aos seus entes queridos e a desatenção ou abandono por parte da equipe profissional, o que tem sido considerado como manifestações de violência institucional e uma violação do direito humano de não ser submetida a tortura ou tratamentos cruéis e degradantes. ${ }^{37}$

Apenas as mães adolescentes contam, no País, com amparo legal nesse sentido no Estatuto da Criança e do Adolescente (ECA):

Os estabelecimentos de atendimento à saúde deverão proporcionar condições de permanência em tempo integral de um dos pais ou responsável, nos casos de internação da criança ou adolescente.

Opera-se aqui uma inversão, pois se atribui a um dos progenitores ou ao responsável, perante a lei, pela menina ou adolescente dando à luz, o direito de acompanhá-la no parto, enquanto que se nega o direito desta última de escolher quem pode melhor the prover suporte. O pressuposto básico é o de que, como em qualquer outra internação, um adulto deve representar a criança ou a adolescente na cena do parto para responder legalmente por ela, dada a necessidade do consentimento informado. Por outro lado, se o intuito da legislação é o de proteger a criança ou adolescente, buscando promover sua saúde, pode-se pressupor que um dos pais ou responsável legal é, necessariamente, a pessoa que pode melhor the prover esse apoio emocional? Em nossa investigação, por exemplo, deparamo-nos com alguns casos de adolescentes que fizeram outras opções quanto ao acompanhamento - optaram por ter ao seu lado durante esse evento seus companheiros e/ou suas amigas. ${ }^{39}$

Tal como o Estatuto da Criança e do Adolescente, a legislação estadual de São Paulo também restringe $o$ direito de escolha da mulher ao definir por ela qual seria seu acompanhante apropriado: "São direitos dos usuários dos serviços de saúde no Estado de São Paulo (...) ter a presença do pai nos exames pré-natais e no momento do parto". ${ }^{40}$

Nesse caso, a legislação determina que o pai da criança é o único acompanhante apropriado. Novamente esse discurso, emanado do legislativo, pressupõe que a cena do parto é um evento que envolve exclusivamente os profissionais de saúde e a família. E, aliás, entende-se por família apenas e tão-somente a família nuclear que, na cena de parto, estaria se constituindo ou ampliando.

Trata-se, mais uma vez, de uma lei restritiva, pois, conforme mostram os dados de nosso trabalho, nem sempre é possível ao pai do bebê estar presente no momento do parto. Tampouco, pode-se dizer que este, ainda que esteja disponível, seja sempre a pessoa de preferência da parturiente para lhe prestar apoio nesse momento.

Assim, o fato de que o pai seja considerado o acompanhante ideal nesse evento se deve, sobretudo, ao modo como se concebem as relações de gênero e a família entre os formuladores de políticas públicas e institucionais. Como vimos, a presença do pai no

\footnotetext{
${ }^{37}$ Ver, a respeito desse tema da violência institucional, Maria ALVES e Antonio SILVA, 2000; Anne DALSGARD, 2000; Cecília MCCALLUM, 1998; DINIZ, 1997, 1998 e 2001; Ana Flavia D'OLIVEIRA, DINIZ e Lilia SCHRAIBER, 2002; e HOTIMSKY et al., 2002.

${ }^{38}$ Estatuto da Criança e do Adolescente, título II, capítulo I, artigo 12 (BRASIL, 1990).

${ }^{39}$ Acerca da opção de adolescentes pelo acompanhamento dos seus parceiros e pais do bebê que está nascendo, ver também CARVALHO, 2001.

${ }^{40}$ Lei n. ${ }^{\circ} 10.241$, artigo 2, inciso XVI (SÃO PAULO, 1999).

${ }^{41}$ SALÉM, 1989.

${ }^{42}$ Acerca da família nuclear moderna como uma construção ideológica, ver FONSECA, 1997; Mariza CORREA, 1993; Robert SLENES, 1993; e Lia MACHADO, 2001.
} 
parto é elemento do ideário do 'casal grávido'41 e da 'família moderna', ${ }^{42}$ cujo referente sociológico coincide, segundo Salém, com a moral das camadas médias urbanas, ditas modernas. Recentemente, a concepção de que o pai seja o acompanhante ideal tem sido incorporada por alguns profissionais de saúde, acadêmicos e formuladores de políticas públicas como um dos aspectos de uma agenda feminista voltada para a melhoria da qualidade da atenção ao parto e ao nascimento, o que é identificado, por vezes, com o movimento pela humanização da assistência. Sua inserção na cena do parto torna-se então um objetivo a ser promovido e uma meta a ser alcançada pelos serviços. Ressalvase que essa não é uma interpretação consensual entre aqueles que defendem a humanização ${ }^{43}$ desse evento, porém nos parece cabível tecer algumas considerações acerca dela, já que é reiterada com certa freqüência.

Partindo do discurso feminista em prol do estabelecimento de relações de reciprocidade igualitárias entre os cônjuges, pautadas por uma complementaridade simétrica, isto é, pelo princípio da igualdade acima referido, argumenta-se que a 'família igualitária' é um valor universal entre as mulheres e que, conseqüentemente, cabe ao profissional de saúde exigir a presença do cônjuge e pai da criança (presume-se que se trata da mesma pessoa) na cena do parto, visando a promover essa mudança nas relações de gênero. ${ }^{44}$

Outro caminho, percorrido por Carvalho, ${ }^{45}$ visando ao mesmo objetivo é o de defender a idéia de que o pai da criança que vai nascer é o acompanhante ideal. Entre os argumentos apresentados pela autora está a idéia de que é seu direito reprodutivo, como genitor, estar presente no nascimento de seu filho/sua filha. Esse argumento faz emergir toda a problemática da naturalização da paternidade que já discutimos em relação à maternidade.

Para além de buscar garantir um direito reprodutivo, trata-se de procurar forjar, por intermédio da cena de parto, um pai, uma mãe e uma família ideal - a família nuclear 'moderna':

Entendendo que o gênero está em formação permanente nos diferentes ambientes sociais, tanto através da construção como da sua desconstrução (...) observamos novas possibilidades de construção da maternidade e da paternidade através da abordagem humanizada do parto e nascimento. Neste tipo de assistência, são respeitadas as vivências emocionais da família: pai, mãe e filho/a além da mulher. Desta maneira, tanto a maternidade como a paternidade são beneficiadas, facilitando a solidariedade e compartilhamento de emoções profundas no nascimento da criança, o que pode contribuir para a construção de relações mais igualitárias entre homens e mulheres.

Afirma-se que a inserção do pai nesse evento é de fundamental importância para que se possa estabelecer vínculos precoces entre pai e filho, visando ao fortalecimento desses laços - o que é considerado uma medida preventiva em relação à violência doméstica contra crianças, o abandono familiar e/ou a delinqüência juvenil -, e para

\footnotetext{
${ }^{43}$ Como mostra DINIZ, 2001, a 'humanização' é um termo que vem sendo utilizado em muitos sentidos diferentes, tendo em torno de seu significado um campo de disputa e de negociação.

${ }^{44} \mathrm{~A}$ esse respeito, ver, por exemplo, o trabalho de BESSA e FERREIRA (1999, p. 46-47) acerca das transformações implementadas recentemente na cena de parto por parteiras tradicionais no meio rural, as quais vêm evidenciando uma das formas típicas de incluir o pai no processo do nascimento como exigência de sua co-responsabilidade pelo evento da gravidez e pela paternidade que deve ser assumida.

${ }^{45}$ CARVALHO, 2001.

${ }^{46}$ CARVALHO, 2001, p. 34.

${ }^{47}$ CARVALHO, 2001, p. 43.
} 
possibilitar a emergência do pai 'cuidador'. ${ }^{47} \mathrm{~A}$ autora reconhece que 0 referente sociológico da proposta de nova paternidade é o da classe média, sendo descrito inclusive como um desdobramento do ideário do 'casal grávido'. Porém, isso não a impede de defender seu caráter universal?

Aliás, ambos os discursos acima referidos defendem a universalização do princípio da igualdade pautada por relações de reciprocidade simétricas e pela indiferenciação em relação aos papéis de gênero, tal como explicitado no ideário do 'casal grávido', e entendem que cabe ao profissional e às instituições de saúde desempenhar um papel significativo em prol dessa mudança na cena de parto. Estes últimos tornam-se agentes de transformação em um evento investido de um enorme potencial transformador.

Uma questão que emerge, aliás bastante recorrente na literatura sobre família no Brasil, é: quais as conseqüências ou repercussões em relação ao modo como são interpretadas as outras formas de organização e estrutura familiares ao se erigir um determinado modelo de família e/ou de paternidade como ideal? ${ }^{48}$ Certamente não são reconhecidas como formas alternativas de organização familiar, mas tendem, como mostram as análises de diversos autores, ${ }^{49}$ a ser ignoradas ou então a ser identificadas como 'tradicionais' e, por isso mesmo, desqualificadas por serem 'resistentes à mudança'. Ou então são percebidas como 'desorganizadas' e, nessa medida, como ambientes menos saudáveis ou até mesmo nocivos para se criar os filhos. Quando se afirma que o modelo de família nuclear moderna e de 'paternidade cuidadora' é mais saudável ou quando a inserção do pai na cena do parto é entendida como medida preventiva em relação à violência doméstica contra crianças, ao abandono familiar e/ou à delinqüência juvenil, não é essa idéia que se insinua? Se os profissionais de saúde aderem a esse ideário e entendem que faz parte de seu papel apoiar esse processo de transformação das relações de gênero na cena de parto, como é que percebem e se relacionam com as pessoas que se inserem em outras formas de organização e estrutura familiares, que não se conformam e não compartilham desse ideal de paternidade e/ou de família?

Essas concepções de família, maternidade e paternidade ideal têm tido repercussão na configuração da cena do parto não apenas no Brasil, mas em outros países do Ocidente. Nos Estados Unidos, a inserção do pai na cena do parto, fruto de movimentos reivindicatórios feministas, é encorajada por profissionais de saúde em alguns hospitais desde pelo menos o início da década de $1960^{50}$ e na França desde pelo menos os anos 1970. ${ }^{51}$ Há maternidades em diversos países ocidentais, particularmente na América do Norte e na Europa, em que o pai é a única pessoa da rede de relações da mulher dando à luz que tem acesso à sala de parto..$^{52}$ Por um lado, isso tem resultado em uma crescente participação do pai nesse evento. ${ }^{53}$ Por outro, tem se tornado um dos temas de confronto entre profissionais de saúde e usuários dos serviços quando estes aderem a distintas concepções das relações de gênero e de família.

\footnotetext{
${ }^{48}$ A esse respeito, ver CORREA, 1993; SLENES, 1993; e FONSECA, 2000.

${ }^{49}$ A esse respeito, ver CORREA, 1993; SLENES, 1993; FONSECA, 2000; e MACHADO, 2001.

${ }^{50}$ MEAD e NEWTON (1967) fazem referência a essa tendência a partir de um estudo de Engels acerca da participação de pais no pré-natal e no parto em um hospital americano em Indiana.

${ }^{51}$ Ver FONSECA, 1997, a respeito da participação de pais em maternidades francesas.

52 Ver nota 14 acima.

${ }^{53}$ Segundo T. D. BERTSCH (1990 apud CARVALHO, 2001, p. 55), a presença do pai no parto nos EUA cresceu muito entre 1973 e 1983, passando de um índice de $27 \%$ para $79 \%$ dos partos realizados.
} 
Em uma maternidade francesa que, em 1991, atendia principalmente mulheres de baixa renda, Fonseca observou a existência de confrontos entre as visões 'tradicional' e 'moderna' nos ritos que circundam o parto. ${ }^{54}$ As equipes médicas haviam criado, desde a década de 1970, alguns ritos para marcar a participação dos pais no parto que incluía, entre outras coisas, a atribuição das tarefas de cortar o cordão umbilical e dar o primeiro banho. Acerca desses ritos a autora comenta:

É normal que os especialistas do parto inventam ritos para acompanhar seu ofício. Porém, esses ritos não são universalmente eficazes. Têm uma significação para aqueles que os criaram; reforçam um sistema de valores ligados à família moderna: intimidade, igualdade entre os esposos, a importância central do vínculo mãe/filho, e a imagem da criança enquanto ser psicologicamente em formação. Um 'lindo parto' seria a condensação em um só retrato desses valores.

Parte da clientela desse serviço não compartilhava desses valores. Provinha de contextos culturais nos quais havia uma nítida segregação entre os papéis de gênero, e a complementaridade entre ambos era o que caracterizava a organização da família. As mulheres que aderiam a esses valores ligados à 'família tradicional' entravam em confronto com a equipe que, como mostra a autora, exercia uma leve pressão visando a inserir o marido na cena de parto:

Uma norte-africana me explica como ela respondeu à parteira que lhe perguntava se seu marido não ia participar do parto: 'Falei para ela, 'Preciso trabalhar. Se meu marido estiver presente, não vou poder me concentrar.' Então a parteira ficou com os olhos desse tamanho, 'Ah é'.

Diante desse confronto, a autora comenta,

O princípio da igualdade entre os sexos que, em um contexto, pode promover a compreensão mútua e a harmonia do casal pode, em outro contexto, contribuir para a neurose individual e a anomia social. ${ }^{57}$

\section{Considerações finais}

Pudemos constatar a existência de uma pluralidade de valores impondo constrangimentos e orientando as opções em relação às formas de acompanhamento entre a clientela do serviço de atendimento ao parto e ao nascimento da ACOMA. Os padrões prevalecentes contrastam com as distintas definições de acompanhante assinaladas nas recomendações e legislações analisadas, pois o evento do parto e do nascimento não é vivenciado, na maioria das vezes, como algo que diz respeito apenas à família ou em que se (re)produz e/ou amplia uma forma específica de família - a família 'moderna'.

Esperamos ter indicado que valores 'modernos' e 'tradicionais' freqüentemente se expressam na cena do parto e que, ao invés de tentar dicotomizar as experiências e significados do parto e do nascimento em 'moderno' e 'tradicional', o que pode resultar em um reducionismo, talvez seja interessante se deter mais na análise da diversidade de experiências e valores que se expressam nesse evento.

\footnotetext{
${ }^{54}$ FONSECA, 1997.

${ }^{55}$ FONSECA, 1997, p. 24.

${ }^{56}$ FONSECA, 1997, p. 24.

${ }^{57}$ FONSECA, 1997, p. 24.
} 


\section{Como afirmam Kalpana Ram e Margaret Jolly,}

Tanto nas tipificações feitas por mães como naqueles feitas nas análises, há uma tendência a dicotomizar nascimento, parto e maternidade em 'tradicional' e 'moderno'. Isto reduz a diversidade de experiências de nascimento e parto em ambas as pontas - pois tanto os padrões 'tradicionais' como os 'modernos' são muito variáveis, não apenas em suas técnicas, mas em suas concepções e avaliações culturais. ${ }^{58}$

Os padrões alternativos de acompanhamento existentes entre a clientela do serviço enfocado e a diversidade de valores explicitados por intermédio desses padrões sugerem que a cena do parto possa ser melhor analisada como uma arena na qual concepções e práticas distintas acerca do parto e do nascimento, assim como de maternidade, paternidade, família e de relações de gênero de modo mais abrangente, se confrontam e se articulam. ${ }^{59}$

A concepção de direito a acompanhante, presente na legislação de São Paulo e no Estatuto da Criança e do Adolescente, de fato, não reconhece a diversidade de valores que orientam as escolhas de acompanhamento entre as gestantes. Essas leis, por esse motivo, ao invés de garantirem direitos universais, passam a ser vistas como instrumento de exclusão social. Na realidade, elas revelam, igualmente, o caráter autoritário do próprio processo de formulação da legislação e de nossa sociedade, à medida que - ao se formularem leis e recomendações, cujos propósitos seriam, a princípio, beneficiar os cidadãos e usuários do sistema de saúde e prover as mulheres grávidas, em particular, do apoio de que necessitam - essas mulheres não são consultadas e nem as pessoas em torno delas que lhes prestam apoio.

Do mesmo modo, quando alguns profissionais de saúde e acadêmicos elegem o cônjuge e/o pai do bebê que vai nascer como acompanhante 'ideal', podem estar exercendo uma intervenção em relação aos valores, formas de organização familiar e estilo de vida das pessoas que constituem sua clientela e que vieram procurar sua assistência. O movimento em prol da humanização do parto e do nascimento tem se empenhado em fazer a crítica ao excesso de intervenções tecnológicas realizadas nesse evento, apoiando-se, para tanto, na medicina baseada em evidências. No entanto, quando, em nome da 'humanização', se defende a disseminação do ideário do 'casal grávido', da 'família moderna' ou do 'pai cuidador' não se estaria buscando transformar a cena do parto em um palco para a realização de novas formas de controle social das subjetividades, das relações de gênero e da família? Nesse caso, a nosso ver, estaríamos entrando em confronto com a própria noção de direitos reprodutivos, pois concordamos, com Denise Dora, que "os direitos reprodutivos querem ser respeitados e protegidos, não regulados e controlados". 60

Nossa perspectiva é a de que a humanização do parto e do nascimento se sustente na concepção multicultural de direitos humanos preconizada por Boaventura Santos, segundo o qual,

(...) Uma vez que todas as culturas tendem a distribuir pessoas e grupos de acordo com dois princípios concorrentes de igualdade e diferença, as pessoas e grupos sociais têm o direito a

\footnotetext{
58 RAM e JOLLY, 1998, p. 14.

${ }^{59}$ Acerca dessa concepção da cena do parto, ver, entre outros, FONSECA, 1997; Cecília VAN HOLLEN, 1994 e 1998 ; Faye GINSBURG e Rayna RAPP, 1991 e 1995; Emily MARTIN, 1992; e Maria A. LOYOLA, 1992.

${ }^{60}$ DORA, 1998, p. 41.

${ }^{61}$ SANTOS, 2000, p. 37.
} 
ser iguais quando a diferença os inferioriza, e o direito a ser diferentes quando a igualdade os descaracteriza.

\section{Referências bibliográficas}

ALVES, Maria T. S. S. B.; SILVA, Antonio A. M. (Orgs.). Avaliação de qualidade de maternidades: assistência à mulher e ao seu recém-nascido no Sistema Único de Saúde. São Luís: Universidade Federal do Maranhão/Núcleo de Pesquisa em Saúde Materno-Infantil/Fundo das Nações Unidas para a Infância (UNICEF), 2000.

BESSA, Lucineide F.; FERREIRA, Sílvia L. Mulheres e parteiras: contribuição ao estudo do trabalho feminino em contexto domiciliar rural. Salvador: GRAFUFBA, 1999.

BRASIL. Estatuto da Criança e do Adolescente. Lei n. 8.069 , de 13 de julho de 1990.

BRASIL. Ministério da Saúde. Parto, aborto e puerpério: assistência humanizada à mulher. 1. ed. Brasília, 2001.

BROWNER, Carole H., and SARGENT, Carolyn F. "Anthropology and Studies of Human Reproduction." In: SARGENT, Carolyn F., and JOHNSON Thomas M. (eds.). Medical Anthropology. Contemporary Theory and Method. Westport Connecticut: Praeger Publishers, 1996. p. 219-234.

CARVALHO, Maria Luiza M. A participação do pai no nascimento da criança: as famílias e os desafios institucionais. 2001. Dissertação (Mestrado) - Programa de Pós-Graduação em Estudos Interdisciplinares em Comunidades e Ecologia Social, UFRJ, Rio de Janeiro.

CHALMERS, lain, ENKIN, Murray, and KIERSE, Marc J. N. C. (eds.). Effective Care in Pregnancy and Childbirth. New York: Oxford University Press, 1989.

CORRÊA, Mariza. "Repensando a família patriarcal brasileira". In: ARANTES, Antonio Augusto et al. (Org.). Colcha de retalhos: estudos sobre a família no Brasil. 2. ed. Campinas: Editora da UNICAMP, 1993. p. 15-42.

COSTA, Rosely G. Concepções sobre maternidade entre mulheres que buscam tratamento para esterilização. 1995. Dissertação (Mestrado em Antropologia Social) - Programa de Pós-Graduação em Antropologia Social, IFCH/UNICAMP, Campinas.

CSORDAS, Thomas J. Embodiment and Experience: the Existencial Ground of Culture and Self. Cambridge: Cambridge University Press, 1994.

CZARNOCKA, Jo; SLADE, Pauline "Prevalence and Predictors of Post-Traumatic Stress Symptoms Following Childbirth." British Journal of Clinical Psychology, v.39, 2000. p. 35-51.

DALSGARD, Anne L. Matters of Life and Longing: Female Sterilization in Northeast Brazil. 2000. Doctoral dissertation presented at the Faculty of Social Sciences, Institute of Anthropology, University of Copenhagen.

DINIZ, Carmen Simone G. Entre a técnica e os direitos humanos: possibilidades e limites da humanização da assistência ao parto. 2001. Tese (Doutorado em Medicina Preventiva) - Programa de Pós-Graduação em Medicina Preventiva, Faculdade de Medicina da USP, São Paulo.

DINIZ, Carmen Simone G. "O que funciona e o que é justo: notas sobre a violência na assistência ao parto". In: DEPARTAMENTO DE MEDICINA PREVENTIVA/ FMUSP. Coletivo Feminista Sexualidade e Saúde/CFSS. Curso de Capacitação para o Atendimento de Mulheres em Situação de Violência. São Paulo, 1997. p. 102-16. Apostila do Curso.

DINIZ, Carmen Simone G. et al. "Not Like Our Mothers. Reproductive Choice and the Emergence of Citizenship Among Brazilian Rural Workers, Domestic Workers and Housewives." In: PETCHESKY, Rosalind P., and JUDD, Karen (eds.). Negotiating Reproductive Rights. Women's Perspectives Across Countries and Cultures. New York: Zed Books, 1998. p. 31-68. 
D'OLIVEIRA, Ana Flavia P. L., DINIZ, Simone G. and SCHRAIBER, Lilia B. "Violence Against Women in Health-Care Institutions: an Emerging Problem." The Lancet, v.359, May 2002. p. 1681 1685.

DOMINGUES, Rosa M. S. M. "Suporte emocional no parto". Saúde em Foco, Rio de Janeiro: Secretaria Municipal de Saúde do Rio de Janeiro, v. 20, ano IX, p. 55-60, 2000. (Informe Epidemiológico em Saúde Coletiva).

DORA, Denise D. "No fio da navalha". In: DORA, Denise Dourado et al. Direitos humanos, ética e direitos reprodutivos. Porto Alegre: Themis - Assessoria Jurídica e Estudos de Gênero, 1998. p. 37-42.

DRESSLER, William W., BALIEIRO, Mauro C., and SANTOS, Jose E. "The Cultural Construction of Social Support in Brazil. Associations with Health Outcomes." Culture, Medicine and Psychiatry, v. 21, 1997. p. 303-335.

ENKIN, Murray, KIERSE, Marc J. N. C., RENFREW, Mary, and NEILSON, James. "Social and Professional Support in Childbirth." In: ENKIN, Murray, KIERSE, Marc J. N. C., RENFREW, Mary, and NEILSON, James (eds.). A Guide to Effective Care in Pregnancy and Childbirth. Oxford: Oxford University Press, 1995. p. 191-197.

FAERSTEIN, Eduardo "O debate qualidade de vida e saúde: outros aspectos a considerar". Ciência \& Saúde Coletiva, v. 5 , n. 1, p. 22-24, 2000.

FERREIRA, Mariana K. L. Sweet Tears and Bitter Pills. The Politics of Health among the Yuroks of Northern California. 1996. Doctoral dissertation presented at the Department of Medical Anthropology, University of California, Berkeley.

FIGUEIREDEO, Regina M. D. Saúde sexual e reprodutiva de mulheres de baixa renda: Favela Monte Azul: um estudo de caso. 1999. Dissertação (Mestrado em Antropologia) Faculdade de Filosofia, Letras e Ciências Humanas da USP, São Paulo.

FONSECA, Claudia Família, fofoca e honra: etnografia de relações de gênero e violência em grupos populares. 1. ed. Porto Alegre: Ed. Universidade/UFRGS, 2000.

"A modernidade diante de suas próprias ficções: o caso da adoção internacional". In: DORA, Denise Dourado et al. Direitos humanos, ética e direitos reprodutivos. Porto Alegre: Themis - Assessoria Jurídica e Estudos de Gênero, 1998. p. 43-60.

. Anatomia de uma maternidade: pesquisadores, profissionais de saúde e pacientes num quadro hospitalar. Porto Alegre, 1997. Mimeografado.

. Caminhos da adoção. São Paulo: Cortez; 1995.

GINSBURG, Faye, and RAPP, Rayna. "The Politics of Reproduction." Annual Review of Anthropology, v. 20, 1991. p.311-343.

. "Introduction: Conceiving the New World Order." In: GINSBURG, Faye D., and RAPP, Rayna (eds.). Conceiving the New World Order. The Global Politics of Reproduction. Berkeley: University of California Press, 1995.

HODNETT, Ellen D. "Caregiver Support for Women during Childbirth." Cochrane Review, Oxford: The Cochrane Library, Issue 1, 2000. Oxford: Update Software.

HOFMEYR, G. Justus, NIKODEM, V. Cheryl, WOLMAN, Wendy-Lynne, CHALMERS, Beverley E., and KRAMER, Tami. "Companionship to Modify the Clinical Birth Environment: Effects on Progress and Perceptions of Labour and Breastfeeding." British Journal of Obstetrics and Gynaecology, v. 98, 1991. p. 756-764.

HOTIMSKY, Sonia N. Parto e nascimento no Ambulatório e na Cassa de Partos da Associação Comunitária Monte Azul: uma abordagem antropológica. 2001. Dissertação (Mestrado em Saúde Materno-Infantil) - Faculdade de Saúde Pública/USP, São Paulo.

HOTIMSKY, Sonia N.; VENANCIO, Sonia I.; BÓGUS, Claudia M.; MIRANDA, Marines M.; RATTNER, Daphne. "O parto como eu vejo... - ou como eu desejo?: representações de gestantes, 
usuárias do SUS, acerca do parto e da assistência obstétrica". Cadernos de Saúde Pública, 2002. No prelo.

KENNELL, John H., KLAUS, Marshall, McGRATH, Susan, ROBERTSON, Steven, and HINKLEY, Clark. "Continuous Emotional Support During Labor in a US Hospital. A Randomized Controlled Trial." JAMA, v. 265, n.1, 1991. p. 2197-2201.

KLAUS, Marshall H., KENNELL, John H., ROBERTSON, Steven S., and SOSA, Roberto "Effects of Social Support during Parturition on Maternal and Infant Morbidity." British Medical Journal, v.293, 1986. p. 585-587.

LOYOLA, Maria A. "Sexualidade e reprodução". PHYSIS. Revista de Saúde Coletiva, v. 2, n. 1 , p. 93-105, 1992.

MACHADO, Lia Z. "Famílias e individualismo: tendências contemporâneas no Brasil". Interface - Comunicação, Saúde Educação, v. 4, n. 8, p. 11-26, 2001.

MADI, B. C., SANDALL, J., BENETTT, R., and MACLEOD, C. "Effects of Female Relative Support in Labor: a Randomized Controlled Trial". Birth, v. 26, n. 1, 1999. p. 4-8.

MARTIN, Emily. The Woman in the Body. A Cultural Analysis of Reproduction. 2a ed. Boston: Beacon Press, 1992.

MCCALLUM, Cecilia Parto como violência em Salvador: perspectivas anthropológicas. 1998. Mimeografado.

MEAD, Margaret, and NEWTON, Niles. "Cultural Patterning of Perinatal Behavior". In: RICHARDSON, S., and GUTTMACHER, A. (eds.). Childbearing: It's Social and Psychological Aspects. Baltimore: Williams and Wilkins, 1967. p. 143-244.

NAÇÕES UNIDAS. Convenção sobre a Eliminação de Todas as Formas de Discriminação Contra a Mulher, 1979. Disponível em: www.direitoshumanos.usp.br/documentos/tatados/ mulher/convencao_sobre_eliminaca.

OSAVA, Ruth H. Assistência ao parto no Brasil: o lugar do não-médico. 1997. Tese (Doutorado em Saúde Materno-Infantil) - Faculdade de Saúde Pública/USP, São Paulo.

OSAVA, Ruth H.; ORTIZ, Argen C. V.; MAGALHÃES, Izumi K.; NAKASHIMA, Maria; MUTA, Matilde M.; SANTOS, Therezinha S. Relatório descritivo das atividades da Casa de Parto de Sapopemba: outubro de 1998 a junho de 2000. Fundação E. J. Zerbini/Secretaria de Estado da Saúde, Programa Saúde da Família - PSF/QUALIS 2

PAIM, Heloisa H. S. "Marcas no corpo: gravidez e maternidade em grupos populares". In: DUARTE, L. F. D.; ONDINA, O. L. (Orgs.). Doença, sofrimento, pertubação: perspectivas etnográficas. Rio de Janeiro: FIOCRUZ, 1998. p. 31-47.

PANOS INSTITUTE. Birth Rights - New Approaches to Safe Motherhood. Londres, 2001. Disponível em: http://www.panos.org.uk/breifing/birth_rights_files/birth_rights.htm.

RAM, Kalpana, and JOLLY, Margaret. Maternities and Modernities: Colonial and Postcolonial Experiences in Asia and the Pacific. Cambridge: Cambridge University Press, 1998.

RIESCO, Maria L. Que parteira é essa? 1999. Tese (Doutorado) - Programa Interunidades de Doutoramento em Enfermagem, Escola de Enfermagem/ USP, São Paulo.

SALÉM, Tânia. "O casal igualitário: princípios e impasses". Revista Brasileira de Ciências Sociais, v. 3, n. 9, p. 24-37, 1989.

SANTOS, Boaventura S. "Por uma concepção multicultural de direitos humanos". In: FELDMANBIANCO, Bela; CAPINHA Graça (Orgs.). Identidades: estudos de cultura e poder. São Paulo: Hucitec, 2000. p. 19-40.

SÃO PAULO (Estado). Lei n. ${ }^{\circ} 10.241$, de 17 de março de 1999.

SLENES, Robert W. "Lares negros, olhares broncos". In: ARANTES, Antonio Augusto et al. Colcha de retalhos: estudos sobre a família no Brasil. 2. ed. Campinas: Editora da UNICAMP, 1993. p. 43- 60. 
TORNQUIST, Carmen S. Paradoxos da humanização: análise de uma experiência de humanização do parto em Florianópolis. 2001. Mimeografado.

UNITED NATIONS. Vienna Declaration and Programme of Action, 1993. Disponível em: www.unhchr.ch/html/menu5/wchr.htm.

VAN HOLLEN, Cecilia C. "Perspectives on the Anthropology of Birth". Culture, Medecine and Psychiatry, v. 18, 1994. p. 501-512.

. Birthing on the Threshold: Childbirth and Modernity among Lower Class Women in Tamil Nadu, South India. 1998. Doctoral dissertation presented at the Department of Medical Anthropology, University of California, Berkeley.

WOLMAN, Wendy-Lynne, CHALMERS, Beverley, HOFMEYR, G. Justus, and NIKODEM, V.Cheryl. "Postpartum Depression and Companionship in the Clinical Birth Environment: A Randomized, Controlled Study." Am J Obstet Gynecol, v. 168, 1993. p.1388-1393.

WORLD HEALTH ORGANIZATION. "Appropriate Technology for Birth.". Lancet, v. 2, n. 8452, Aug. 1985. p. 436-437.

\section{Defining who Lends Support to Whom in Childbirth: an Ideological Issue?}

Abstract: Medical, juridical and public health discourses recognize the importance of support in labor and childbirth. However, the way in which the person responsible for lending support in this event is defined varies in the diverse discourses being considered. We describe patterns of support in the birth scene of an 'alternative' health service with a proposal of out-of-hospital midwifery assistance, discussing the relation between these patterns o accompaniment and different form of sociability, including gender relations, in existence among the women of different social origins who frequented this service. Finally we discuss the limits imposed, primarily by Sao Paulo State legislation and by the Estatuto da Criança e do Adolescente [National Statute of the Child and Adolescent], to the range of "options" of support people made eligible to the woman giving birth and to the members of her social network.

Key words: Support in labor and childbirth; family; gender relations 